\title{
The Research of Comprehensive Quality Evaluation for Distant Education
}

\author{
Mu Dan \\ Xi'an International Studies University, XiAn, China \\ Email: mudan_michelle@yahoo.com.cn \\ Liu Ming-Li \\ Chengdu Neusoft Institute of Information, ChengDu, China \\ Email: liuml@neusoft.com
}

\begin{abstract}
The study on the quality evaluation and the related technology on distant education can provide evidence for the quality teaching and learning, and ensure the high quality and efficiency for distant education. It is highly significant to construct the teaching resources and learning supporting system by establishing an appropriate system that fits the level of education and guarantees the teaching quality. On the basis of the research results of programs, standards and technology for the quality evaluation of the distant education, this essay puts forward a method of comprehensive quality evaluation by applying the theory of comprehensive evaluation into this area, which is a quantitative research about how to set and calculate the weight indices for the evaluation. This method can process the quality indices by quantity efficiently, give a direct view of the quality by the comparative analysis, and provide the evidence for improving the quality.
\end{abstract}

Index Terms—f Distant Education; Quality; Evaluation;

\section{INTRODUCTION}

At present, the study and experience on the evaluation of distant education have not been much in our country. There hasn't been any systematic and standard model. The exploration and study on this are highly significant for gaining valuable experience for the construction of distant education model, promoting the course construction and the teaching approaches to be modernized, scientific and standardized, the construction of learning resources and support system for distant education, and the establishment of quality system appropriate to the education itself $[1,2,3]$.

The study on the theory and technology on the evaluation of quality distant education does not only propel the development of distant education and measures of online education[4,5], but also guarantees the learners to get high quality service so that they can achieve, progress and apply what they learn online. The advanced computer and network technology makes it possible to build the evaluation system appropriate to the education itself. The network - highly interactive, distributive, open in time and space, convenient in data collection and management, individualized in communication and fast in statistical reports and analysis - has been used in the technological area of education evaluation, expanding the scope and bringing about breakthroughs.
The evaluation of distant education consists of the value judgment, the evaluation development and standards for reference[6,7]. With the set goals for the education, this means to analyze, assess and evaluate the performance, effect and accomplishments of the open education activities and the quality of learners' learning and development by the technological approaches of modern education measurement and information processing to get the profound evidence via data collection and processing, for the purpose of exploring the laws of education and promoting the adjustment of the education programs and the improvement of the conditions, the level, quality and efficiency of the education, so as to reach the goals.

In the field of distant education, there have been some studies about its quality evaluation with their methods for evaluation and index system[8]. Some index systems are quite effective, like the one for evaluating the multimedia materials in the education resources, the one for evaluating software resources and the one for online course evaluation. There are also systems designed for the evaluation of some specific parts of education.

This essay, based on the existing programs, standards and technology of distant education evaluation, puts forward a method of analytical hierarchy process on the basis of comprehensive evaluation, applies the theories and approaches of comprehensive evaluation into distant education, and makes a quantitative research about the setting and calculation of the weight indices for evaluation.

\section{The CONCEPT OF Distant EdUCATION System}

The process of quality evaluation of distant education is the one that evaluates and assesses the education value of the system and grades the system. The education value of a distant education system is reflected by its program and level that help achieve the educational goals. With the basic role of education as to prepare the learners for their future development, the education value of the distant education system is measured by whether or not it can provide the help learners need for their future development.

A system is an integrated whole of many parts interacting and depending with each other. By the accepted definition of the system concept, the concept of 
distant education system, in the opinion of the author, can be defined as: the distant education system is an integrated whole with the key components of educators, learners, media, channels, administration (management), evaluation and so on, interrelating and interacting with each other to prepare talents for the social and cultural development.

To get an in-depth understanding of this concept, the following must be taken into account (the attention must be drawn to the following):

1)The key components of the distant education system consist of educators, learners, media, channels, administration and so on.

2)The function of the distant education system is to prepare talents via the means of education for the social and cultural development.

3)It is an open social system exchanging with the materials, energy and information of the outside world.

4)There are 3 levels in distant education system: development strategy and macro decision-making, education mode and administration, and the course of education.

\section{A The Basic Mode of Distant Education}

Being time-bound or not, modern distant education systems (Internet-based) can be divided into real-time system which is in synchrony with the teaching, and the non real-time system which is not. The related technology- TV broadcast, video TV, cable TV and satellite digital channels-with the two teaching modes is also different and with each of their own strength and weakness. Generally speaking, the technological application for modern distant education is Internet oriented, with the internet as the theme of distance education and other technologies as supplements.

\section{1) Real-time Distant Education Mode}

In the implementation of real-time education mode, a distant education center and some distant classroom are set up in the distant education web for the teaching, lectures and discussions. Each classroom is facilitated with a digital whiteboard, camera, monitors, scanner, projector, mike, loud speakers and so on. Teachers give their lesson by the schedule in the syllabus in the education center and their dynamic video, voice and teaching PPT are transmitted to the local and distant classrooms with the help of the facilities. In the teaching, teachers can use either the prepared PPT or whiteboard, and display information via scanner and projector. In this real-time education mode, it is the same as the face-toface teaching for the students to raise question from the local or distant classrooms, and for teachers to answer these questions and check upon students' learning in each different classrooms by switching the monitors and control unites.

\section{2) Non-Synchrony Education Mode}

Non-synchrony education mode is also called non realtime education mode, which is web-based multimedia education-the distant website education mode. Non realtime education is good for individuals to choose the teaching content, time, teaching mode or even tutors according to their own wish and needs. Learners can learn through their computers at home or office, or portable machine on their travels.

\section{B.The Elements of the System}

All the necessary resources for the distant learning are regarded as the elements of the distant education system, which can be divided and analyzed from learners' perspective into the following;

The element of teachers:Teachers, here in broad sense, include not only those who deliver the lesson but also compilers of the textbooks, designers of the course, programmers, those of multi-media producing and so on. Teachers are a team, collaborating to finish the course design and making and the construction of other learning resources.

The Element of Learners:Apart from each individual leaner, it also refers to the groups formed these individuals and the relationship between them. Learns, both as the receiver and the sender of the education distribution, put forward their learning needs and drive forward the operation of the distant education system with the interaction among them for the exchange and share of information.

The Element of Information:In distant education, information broadly refers to the learning content, teaching resources, information feedback and control, and so on. This element is for the analyzing the features and the distribution course of the information.

Learning Support Element (The Element of Media Channel):It includes the communication network, terminal equipment, application system, and each individual teaching center.

The Element of Administration:It refers to school management, teaching administration, the development of courses and materials, and the quality control and evaluation. The traditional administration content is seamlessly linked between the system levels and the service levels into an interface, via which learners can know about their file and related information with the help of Internet and voice mail.

The Element of Evaluation:As a key component of quality evaluation of the distant education system, this element includes the index system of education quality evaluation, evaluation methods and schemes, the test and evaluation of learning effect.

\section{C.The Quality Evaluation Mode of Distant education}

From the perspective of communication, teaching activities are a course of transferring the information. Modern distant teaching activities are special course of information transfer via the technological means based on network. To elaborate the structure of this course and the relationship between the elements which build up the course, modeling is necessary. "Mode" is a theoretical and concise expression of the object world. Dautch, a famous expert in communication, puts forward that mode is "the rule of the structure and operation of a symbol, which links the existing structure and course with the related important elements". Communication mode serves as the key to the correct understanding of the communication activities, revealing the order of the sub- 
systems and elements, the form of the structure and relations with the outside world. Thus, it is possible to get a full picture, when any of the elements is analyzed, about the complex relationships and interactions of this element with others. Teaching actually is the interaction between teachers and students, who enjoy an equal relationship in modern distant education, which is different from the traditional classroom teaching with teachers as the subject and students as the object, from that with students as the only subject and teachers as the object.

In modern distant teaching activities, there involves the face-to-face interaction between the teachers and students, but just relatively less. The major interactions are achieved via the teaching interactive channel based on network and other modern information technologies. Though, relatively separated in time and space, these interactions can be in or not in synchrony. According to Shram, the two-way cycle mode refers to the equal communication between two individuals and the range of their common experience has a direct influence on the range and depth of the communication between these two individuals. Hence, there should be a profound understanding of the learners first before the study of the feedback, which is the study of interaction.

This essay specifies the elements that affect the teaching effect - the teaching quality-from the perspective of a system. When in order, these elements are who-teacher element, talks about-teaching content, through-teaching platform, to whom-students, to the effect-teaching quality. Based on the analysis of distant education system, the author thinks such a model of modern distant education evaluation can be constructed:

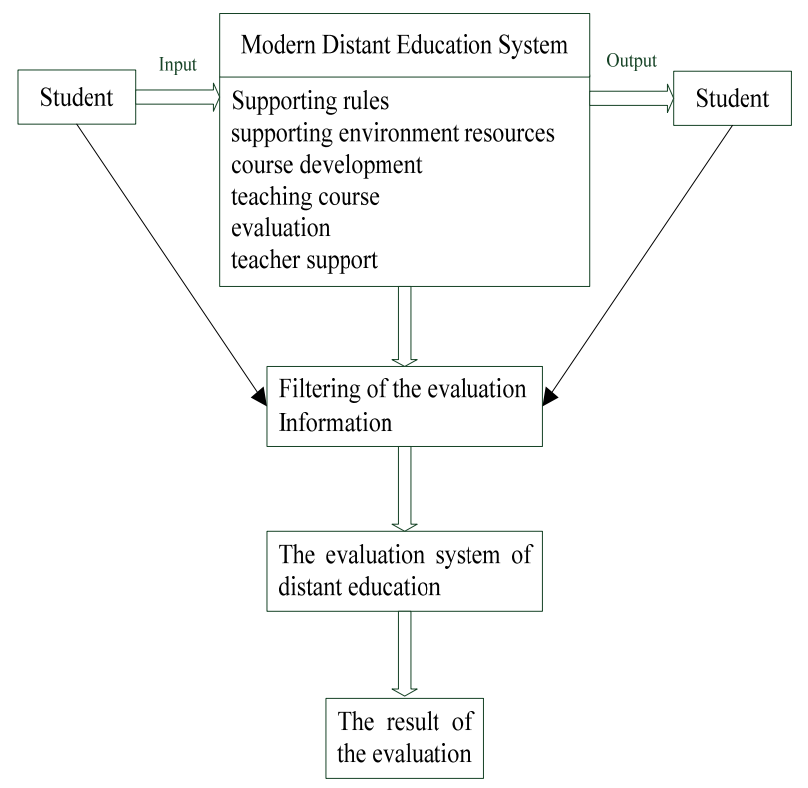

Figure 1. Model of Distant Education Evaluation

\section{The Process of Distant EdUCATION EVALUATION}

The evaluation of distant education has to go through a process that includes setting the target and goals, making the plan, organizing the personnel, the implementation of the plan, data collection and processing, and the feedback of the processed results.

The preparation of evaluation mainly is about setting the target and goals, making the evaluation plan and the organization and training of the people for the evaluation. It is the first step to set the target of evaluation in distant education in line with the principle of being beneficial, easy to implement and clear. The goal of evaluation should consist two parts: the standards with the values common in education evaluation and the standards especially valuable for distant education. Making the evaluation plan is the essential part, which includes the establishment of the index system, the collection method and the processing technology for each index, the organization and the work schedule of the evaluation. In this plan, the index system is the core and the basis for conducting evaluation of modern distant education. It has to aim at the target and goals of the evaluation to decide the source data and what technology and method to adopt for the data processing.

The implementation is mainly about data collection by the methods for each index designed in the evaluation plan. In the phase of data processing and feedback, the data information has to be analyzed by quantity and attributes. For the quantitative analysis, it needs to set up math models and design and develop program for processing the collected data. The result of which is used to evaluate the teaching activities and draw the conclusions. A report is given as feedback together with advices for improvements.

By the task and the time of taking place, the evaluation can be divided into forming evaluation and summary evaluation. In distant education, to provide the learning objectives, contents and strategies appropriate for the learners, it is also necessary to give a diagnostic evaluation of the learners.

The diagnostic evaluation refers to the evaluation of learners before they start learning, which is given before a course or a unit to assess learners' level in knowledge, feeling and skills so as to make the teaching meet the needs and background of the learners. The result of which will be taken as evidence for the course design, the selection for contents and teaching methods, and for the learners to make learning goals and plan and select the learning methods and contents. In the online teaching diagnostic assessment, it is by the goal of evaluation that the learners' knowledge and ability are measured. Questionnaires are used to get the information about learners' knowledge, learning conditions, needs and attitudes. The evaluation outcome is drawn from the data captured in the measurement and the statistics from the questionnaire. All this makes it possible in the teaching to divide the learners into groups and provide different learning resources that fit each of them. And the teaching design, progress, strategies and methods are chosen to fit the learners according to their different characteristics. This evaluation is only targeted at the learners.

The forming evaluation refers to the continuous assessment throughout the whole process of a teaching 
activity for the purpose of making it better. It allows us to understand the teaching efficiency of teaching and the learners' progress and problems in a period. With the intime feedback, the teaching is adjusted and improved in time. As the forming evaluation is done during the course, all the efforts should be devoted to the improvement of this course. This principle lays the emphasis on the tracking and feedback of the teaching system in the process of real-time teaching and learning so as to identify the problems and give the feedback to learners, or make-up measures or plans are given to reduce the loss. Along with the tracking, the emphasis is also put on investigating whether the learners are motivation-driven, their attitude and their learning progress so that descriptions, warnings and suggestions are given. Once the teaching program is deployed, teachers collect the timely feedback for evaluation so as to find out the teaching and social value of the teaching program, whether the expected goals and efficiency are met, and strengths and weakness, to provide encouragement, reminding and guidance for the coming learning, and to make adjustment and suggestions about the teaching. All these work is also important for the improvement of the whole teaching system, which can only meet the needs of the learners with a continuous effort for improving the functionality, so that the distant learning can enjoy a sustainable development.

The summary evaluation normally refers to that given at the end of the period when the teaching is finished. It aims to see to what extent the teaching goals are achieved, review the work of teaching, and assess the learners' final score so as to understand the efficiency of teaching and give the final evaluation and result for the teaching and learning. In online teaching, the summary evaluation gives the final comments and results about all the learning activities of the learners, and the teaching performance of the teachers, even including the completion of learning, the graduation, the decision on awards and the evaluation of teachers.

\section{The Method of Multi-Attribute COMPREHENSIVE EVALUATION}

As a combination of modern communication technology and education, online education has its advantage over other forms of education. The studies about rules and characteristics of online education are just at still at its early stage. It is highly expected to build an effective system for quality evaluation and control. Some experts and researchers in distant learning have put forward many programs, standards and technologies for the quality evaluation of the distant learning, many of which can be applied and used for reference.

Facing the already designed evaluation indices, how to decide the priority of them as the function of each index in the comprehensive evaluation and their different weight are different? With the reference to the views of the experts and the importance placed on the roles of teachers and learners, this essay puts forward a method of analytical hierarchy process based on comprehensive evaluation, applying the theory and methods in the quality evaluation of distant learning, that sets, calculates and gives a quantitative study of the weights of the indices.

\section{A. The Multi-Attribute Comprehensive Evaluation}

In our daily life, we often have to make all kinds of judgment, like which university enjoys a good fame. To judge whether a university is good, we need to compare several universities from the aspects of their scale, teaching quality, research outcomes, the location of the campus and so on. The process of giving the answer is the just the process of evaluation and a process of decision making with limited programs.

The comprehensive evaluation refers to the overall subjective, just and reasonable evaluation of a target. If this target is seen as a system, the above questions can be expressed abstractly like this: in several (similar) systems, how to distinguish which one operates well or which doesn't? This is a very common comprehensive judgment question - the comprehensive evaluation problem. For the decision-making from limited several programs, comprehensive evaluation is the prerequisite for the decision making. The right decision only comes from the scientific comprehensive evaluation.

Generally speaking, the elements for comprehensive evaluation consist of the following:

(a) The Object of Evaluation:The units digit is bigger than one for the targets of the same category. Assume (all for the same category) that the targets for evaluation and the system are marked respectively as: $s_{1}, s_{2}, \ldots s_{\mathrm{n}} \quad(\mathrm{n}>1)$

(b) The Evaluation Index:The operation of each system (or the development of the systems) can be expressed by vector $X$, among which each component reflects the condition of the system from its perspective. Thus, $\mathrm{X}$ is the system's condition vector and works as the index for the system's condition of operation. Generally, in creating the index system, the rules to abide by are: systematic, scientific, comparable, measurable, and (as much as possible) independent. Without loss of generality, assume that there are $m$ items of index and marked respectively as: $x_{1}, x_{2}, \ldots, x_{\mathrm{m}}(m>1)$.

(c) Weight Coefficient :In regard to the purpose of evaluation, the relative importance between each index can be different. The relative magnitude of this importance between the indices can be marked by the weight coefficient. Assume that $\omega_{\mathrm{j}}$ is the weight coefficient of index $x_{\mathrm{j}}$, generally $\quad \omega_{\mathrm{j}} \geq 0$ $(i=1,2, \ldots, m), \sum_{i=1}^{m} \omega_{i}=1$

(d) The Model of Comprehensive Evaluation: The compre-hensive evaluation with multiple indices (or attributes) refers to the math model (or algorithm) that combines multiple assessment indices into comprehensive evaluating values as a whole. That is to say, on the basis that there are $n$ elements of evaluating values $\left\{x_{\mathrm{ij}}\right\}(\mathrm{i}=1,2, \ldots, \mathrm{n} ; \mathrm{j}=1,2, \ldots, \mathrm{m})$, how to choose or construct $\omega=\left(\omega_{1}, \omega_{2}, \ldots, \omega_{\mathrm{m}}\right)^{\mathrm{T}}$ in $y=f(\omega, x)$ as the index weight vector and $\mathrm{X}=\left(x_{1}, x_{2}, \ldots, x_{\mathrm{m}}\right)^{\mathrm{T}}$ as the state vector of the coefficient. From these algorithm, what can be drawn 
is that the comprehensive assessment values $y_{i}=f\left(\omega, x_{i}\right)$, $\mathrm{X}_{\mathrm{i}}=\left(x_{\mathrm{i} 1}, x_{\mathrm{i} 2}, \ldots, x_{\mathrm{im}}\right)^{\mathrm{T}}$ are the condition vector $(\mathrm{i}=1,2, \ldots, \mathrm{n})$ of the $i$ th System, and $n$ elements of systems can be sorted or categorized according to the value of $y_{i}$ (from small to big or big to small).

\section{B. Analytical Hierarchy Process}

Analytical hierarchy process (AHP) is one of the comprehensive evaluation methods, which is shown as Figure.2. In systematic analysis of social, economic and scientific management problems, what we often come across is a very complex system with many factors that are interrelated and inter-constrained. Analytical hierarchy process is a easy and practical solution to this kind of complicated problems.

The idea and process of AHP can be divided into the following steps:

1) Construct the Comparative Judgment Matrix for Pairs

After the construction of hierarchical structure, the relationship of subordination is set up. Assume that element $a$ as the principle of the upper level and it has a dominance over the elements $x_{1}, x_{2}, \ldots, x_{\mathrm{n}}$ of the lower level so that the corresponding weight of $\omega_{\mathrm{i}}(\mathrm{i}=1,2, \ldots, \mathrm{n})$ to $x_{i}$ is given according to their hierarchy under the principle $a$. For most of the social and economic problems, especially when people have to judge the importance of an issue, it is never easy to get the weight of these elements directly. AHP adopts the comparative judgment for pairs to compare the impact of $n$ elements of $x_{1}, x_{2}, \ldots, x_{\mathrm{n}}$ to principle $a$, so as to pin down their proportions in principle $a$. Take two elements $x_{\mathrm{i}}, x_{\mathrm{j}}$ each time and use $a_{\mathrm{ij}}$ as the comparative degree of their relative importance, the overall result of comparison can be expressed by $A=\left(a_{\mathrm{ij}}\right)$, which is called comparative judgment matrix.

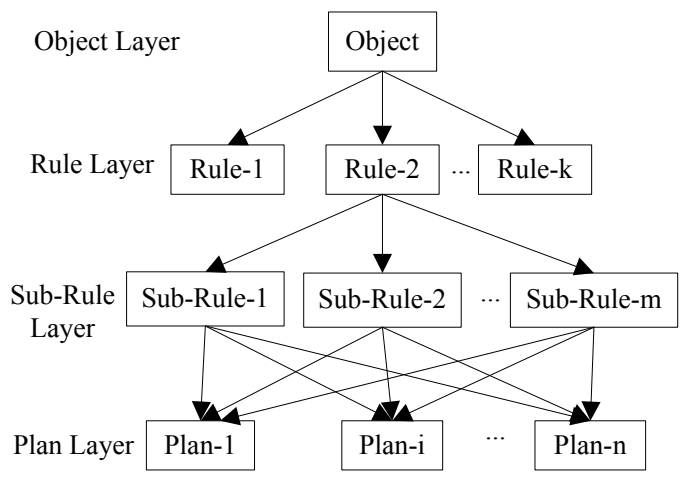

Figure 2. Analytical hierarchy process

The basis or source of the assigned value of aij (Figure 3) can be provided by the decision maker, or decided via their dialogue, or acquired through technological consulting done by an analyst, or decided by other means what they think fit.

\begin{tabular}{|c|c|}
\hline $\begin{array}{c}\text { Assigned } \\
\text { Value }(x \mathrm{x} / \mathrm{xj})\end{array}$ & Explanation \\
\hline 1 & $\begin{array}{l}\text { To compare index } x i \text { with index } x j \text {, they } \\
\text { are at the same degree of importance }\end{array}$ \\
\hline 3 & $\begin{array}{l}\text { To compare index xi with index } x j \text {, index } \\
x i \text { is a bit more important than index } x j \text {. }\end{array}$ \\
\hline 5 & $\begin{array}{l}\text { To compare index xi with index } x j \text {, index } \\
x i \text { is obviously more important than } x j\end{array}$ \\
\hline 7 & $\begin{array}{l}\text { To compare index } x i \text { with index } x j \text {, } \\
\text { index } x i \text { is much more important than } x j\end{array}$ \\
\hline 9 & $\begin{array}{l}\text { To compare index xi with index } x j \text {, index } \\
x i \text { is extremely more important than } x j \text {. }\end{array}$ \\
\hline $2,4,6,8$ & $\begin{array}{l}\text { They correspond to the middle degree of } \\
\text { the two judgments next to each other }\end{array}$ \\
\hline $\begin{array}{l}\text { To count } \\
\text { backward }\end{array}$ & $\begin{array}{l}\text { To compare } x j \text { with index } x i \text {, the } \\
\text { judgment result is ajj=1/ajj. }\end{array}$ \\
\hline
\end{tabular}

Figure 3. The explanation of assigned value

\section{2) The Calculation of the Relative Weight of Each} Element .

The judgment matrix A is got through the comparative judgment for pairs about the elements $x_{1}, x_{2}, \ldots, x_{\mathrm{n}}$, Assume that $\mathrm{A}$ is a consistent matrix, $\omega=\left(\omega_{1}, \omega_{2, \ldots,}, \omega_{\mathrm{n}}\right)^{\mathrm{T}}$, got through solving the problem with the eigenvalue of the matrix and then normalized into elements of $x_{1}, x_{2}, \ldots$, $x_{\mathrm{n}}$, are sorted. This method is called the eigenvalue of calculating the sorting weight vector.

3) Test on the Consistency of the Judgment Matrix

Quite often, anyone who makes the judgment can identify the difference between the value of $a_{\mathrm{ij}}$ and the objective existence of $\omega_{\mathrm{i}} / \omega_{\mathrm{j}}$. It is necessary to test on the consistency of the constructed judgment matrix.

Based on the theory of matrix, the variables of the eigenvalue of the matrix can be used for testing the degree of the consistency of the judgment matrix. The quantitative index for measuring the consistency is called C.I. (consistent index). Saaty T. L. defines it as C.I. $=\left(\lambda_{\max }-m\right) / m-1$ and proposes to use the average R.I (random consistency) to revise C.I.

The process of calculating the average R.I. (random consistency) index is as follows:

In regard to the fixed value $m$, choose the value of $m(m-1) / 2$ randomly and independently from $1,2, \ldots, 9,1 / 2, \ldots, 1 / 9$ as the element of matrix's upward triangle, the element of main diagonal is assigned 1 , the element of downward triangle is assigned the reciprocal, then we get the random orthogonal inverse matrix A'.

The calculation gives the consistency index of A: R.I. $=\left(\lambda_{\max }^{\prime}-m\right) / m-1$

Repeat the above steps to get enough amounts of samples. Calculate the average value of R. I. samples. The average value of R.I. of 1000 samples is given in Figure 


\begin{tabular}{|c|c|c|c|c|c|c|c|}
\hline $\mathrm{m}$ & 2 & 3 & 4 & 5 & 6 & 7 & 8 \\
\hline R.I. & 0 & 0.51 & 0.89 & 1.11 & 1.24 & 1.34 & 1.42 \\
\hline $\mathrm{m}$ & 9 & 10 & 11 & 12 & 13 & 14 & 15 \\
\hline R.I. & 1.46 & 1.48 & 1.51 & 1.54 & 1.55 & 1.57 & 1.58 \\
\hline
\end{tabular}

Figure 4. The average value of R.I

The two order judgment matrix can be consistent eventually. When the matrix's order is bigger than 2, The result of compare C.I. with R.I. is called C.R. When the C.R. $=$ C.I. $/$ R.I. $<0.1$, the judgment matrix has nonconsistency; Otherwise, initializing judgment matrix is not good and need to be assigned value again until the consistent is checked rightly.

4) Test on the Consistency of the Combined Weight of Elements (program plan) and the Overall Consistency

If a system can be divided into three layers, assuming the top layer as $\mathrm{z}$, the second layer as $\mathrm{Y}=\left\{\mathrm{y}_{1}, \mathrm{y}_{2}, \ldots, \mathrm{y}_{\mathrm{n}}\right\}$ and the third layer as $\mathrm{X}=\left\{x_{1}, x_{2}, \ldots, x_{\mathrm{m}}\right\}$, and the weight vector of $\mathrm{Y}$ to $\mathrm{z}$ as $\omega_{\mathrm{z}}(\mathrm{Y})=\left(\omega_{\mathrm{z}}\left(\mathrm{y}_{1}\right), \omega_{\mathrm{z}}\left(\mathrm{y}_{2}\right), \ldots, \omega_{\mathrm{z}}\left(\mathrm{y}_{\mathrm{n}}\right)\right)^{\mathrm{T}}$ and $\mathrm{C} . \mathrm{I}_{\mathrm{yi}}(\mathrm{X})(\mathrm{i}=1,2,-\ldots \mathrm{m})$, the proportion of $x_{\mathrm{j}}$ in $z$ is:

$$
\omega_{\mathrm{z}}\left(\mathrm{x}_{\mathrm{j}}\right)=\sum_{i=1}^{n} \omega_{y_{j}}\left(x_{j}\right) \omega_{z}\left(y_{i}\right), j=1,2, \ldots, \mathrm{m} .
$$

If $r_{\mathrm{ij}}=\omega_{\mathrm{yj}}\left(x_{\mathrm{j}}\right), \mathrm{R}=\mathrm{R}\left(r_{\mathrm{ij}}\right)$, the above equation can be expressed by vector: $\omega_{\mathrm{z}}(\mathrm{X})=\mathrm{R} \omega_{\mathrm{z}}(\mathrm{Y}) . \quad \omega_{\mathrm{z}}$ $(\mathrm{X})=\left(\omega_{\mathrm{z}}\left(x_{1}\right), \ldots, \omega_{\mathrm{z}}\left(x_{\mathrm{m}}\right)\right)^{\mathrm{T}}$ is the about the vector of $\mathrm{X}$ about z. $\omega_{\mathrm{z}}(\mathrm{Y})=\left(\omega_{\mathrm{z}}(\mathrm{y} 1), \ldots, \omega_{\mathrm{z}}(\mathrm{yn})\right)$ is the vector of $\mathrm{Y}$ about $z$.

As to the $C . I_{z}(Y)$ and $C . I_{y i}(X)(i=1,2, \ldots$, , the consistency index of $\mathrm{X}$ about $\mathrm{Z}$ is defined as $\mathrm{C} . \mathrm{I}_{\mathrm{z}}(\mathrm{X})=\mathrm{C} . \mathrm{I}_{\mathrm{z}}(\mathrm{Y})+\sum_{i=1}^{n} \omega_{z}\left(y_{i}\right)$ C. $\mathrm{I}_{\mathrm{yi}}(\mathrm{X})$. The corresponding randomizing consistency index is

$$
\text { R. } \mathrm{I}_{\mathrm{z}}(\mathrm{X})=\mathrm{R} . \mathrm{I}_{\mathrm{z}}(\mathrm{Y})+\sum_{i=1}^{n} \omega_{z}\left(y_{i}\right) \text { R. } \mathrm{I}_{\mathrm{yi}}(\mathrm{X}) \text {. }
$$

\section{The Algorithm of Sorting Weight}

What introduced here is one of the methods: use the square root law (averaging method) to get the characteristic vector corresponding to the maximum eigenvalues of the judgment matrix.

Assume $\mathrm{m}$ phase judgment matrix is $\mathrm{A}=\left(a_{\mathrm{ij}}\right)$.

Multiply the elements one after another, and extract a root of $m$. This is to get the geometrical mean;

$$
\left.b_{\mathrm{i}}=\left(\prod_{j=1}^{m} a_{i j}\right)\right)^{1 / m}, \mathrm{i}=1,2, \ldots, \mathrm{m} .
$$

Then normalize $b_{\mathrm{i}}(\mathrm{i}=1,2, \ldots, \mathrm{m})$ and we get the weight of index $x_{\mathrm{j}}$ :

$$
\omega_{\mathrm{j}}=\mathrm{b}_{\mathrm{j}} / \sum_{k=1}^{m} b_{k}, \mathrm{j}=1,2, \ldots, \mathrm{m} .
$$

Whether the method of the square root law is reasonable can be explained by the conditions for consistency of A.

\section{The Approximate Calculation of $\lambda_{\max }$}

To test for the consistency of the judgment matrix, $\lambda_{\max }$, as the biggest value of the judgment matrix used in C.I, needs to be calculated.

Assume $m$ level of the judgment matrix as $\mathrm{A}=\left(a_{\mathrm{ij}}\right)$, and the eigenvalue of A's normalization has been got as $\omega=\left(\omega_{1}, \omega_{2}, \ldots, \omega_{\mathrm{m}}\right)^{\mathrm{T}}$

And assume that the maximum value of the judgment matrix is $\lambda_{\max }$. Expand the characteristic equation of matrix $\mathrm{A} \omega=\lambda_{\max } \omega$, we get:

$$
\sum_{j=1}^{m} a_{i j} \omega_{j}=\lambda_{\max } \omega_{i}, \mathrm{i}=1,2, \ldots, \mathrm{m} .
$$

Divide the both sides by $\omega_{\mathrm{j}}$ and then add $i$ then we get $\lambda_{\max }=\sum_{i=1}^{m}\left(\sum_{j=1}^{m} a_{i j} \omega_{j}\right) / \omega_{i}$.

\section{THE APPLICATION OF THE COMPREHENSIVE EVALUATION METHOD}

Apply the method of hierarchy analysis into the calculation of the weight for the index system of evaluating the teaching course of the distant education, and compare with the comprehensive evaluation value acquired from the teaching course projects of each term. The following chart, taken in this essay as the index system for the quality evaluation of the teaching course of distant education, is used to show how the weight and the comprehensive evaluation value are calculated. 


\begin{tabular}{|c|c|c|}
\hline L1 Index & L2 Index & L3 Index \\
\hline \multirow{5}{*}{ Import the courses } & \multirow{3}{*}{ Teacher } & Make-up of personnel \\
\hline & & Syllabus \\
\hline & & Content Update \\
\hline & Students & Learning skills \\
\hline & Resources & Teaching resources \\
\hline \multirow{5}{*}{ Learning support } & $\begin{array}{l}\text { Supporting } \\
\text { environment }\end{array}$ & $\begin{array}{l}\text { Supporting system for } \\
\text { network-base learning }\end{array}$ \\
\hline & Supporting Personnel & Make-up of the personnel \\
\hline & \multirow{3}{*}{ Supporting content } & Learning assistance \\
\hline & & Learning methods \\
\hline & & Mind-set adjustment \\
\hline \multirow{2}{*}{ Teaching evaluation } & Student assessment & Ways of assessment \\
\hline & Course evaluation & $\begin{array}{l}\text { Satisfaction level of the } \\
\text { students }\end{array}$ \\
\hline
\end{tabular}

Figure 5. Index of Evaluation

Take the above authentication index of each level of the teaching course in distant education as the rules of each level in the level analysis method, index as that of evaluation, and the relative importance of the index decided after consulting the experts, teacher, administration staff, and students, we get the following comparative matrix.

$$
\begin{aligned}
& A=\left[\begin{array}{llll}
1 & 1 / 3 & 1 / 3 & 1 \\
3 & 1 & 1 & 3 \\
3 & 1 & 1 & 3 \\
1 & 1 / 3 & 1 / 3 & 1
\end{array}\right], \\
& b_{1 j}=0.577, b_{2 j}=1.732, b_{3 j}=1.732, b_{4 j}=0.577, \\
& \omega_{1}=b_{1 j} / \sum_{i=1}^{4} b_{i j}=0.125, \omega_{2}=0.375, \omega_{3}=0.375 \text {, } \\
& \omega_{4}=0.125 \text {. } \\
& A \omega=\left[\begin{array}{llll}
1 & 1 / 3 & 1 / 3 & 1 \\
3 & 1 & 1 & 3 \\
3 & 1 & 1 & 3 \\
1 & 1 / 3 & 1 / 3 & 1
\end{array}\right]\left[\begin{array}{l}
0.125 \\
0.375 \\
0.375 \\
0.125
\end{array}\right]=\left[\begin{array}{c}
0.5 \\
1.5 \\
1.5 \\
0.5
\end{array}\right], \\
& \lambda_{\max }=\frac{1}{4}\left[\frac{0.5}{0.125}+\frac{1.5}{0.375}+\frac{1.5}{0.375}+\frac{0.5}{0.125}\right]=4 \text {, } \\
& \text { C.I. }=\left(\lambda_{\max }-4\right) /(4-1)=0, \text { R.I. }=0.8931 \text {,C.R. }=\text { C.I. } / \text { R.I. }<0.1 \text {, }
\end{aligned}
$$

$$
\begin{aligned}
& A^{\prime}=\left[\begin{array}{lll}
1 & 5 & 3 \\
1 / 5 & 1 & 1 \\
1 / 3 & 1 & 1
\end{array}\right], \\
& b_{1 j}^{\prime}=2.44, b_{2 j}^{\prime}=0.588, b_{3 j}^{\prime}=0.696, \\
& \omega_{1}^{\prime}=b_{1 j}^{\prime} / \sum_{i=1}^{3} b_{i j}^{\prime}=0.655, \omega_{2}^{\prime}=0.158, \omega_{3}^{\prime}=0.187, \\
& A^{\prime} \omega^{\prime}=\left[\begin{array}{lll}
1 & 5 & 3 \\
1 / 5 & 1 & 1 \\
1 / 3 & 1 & 1
\end{array}\right]\left[\begin{array}{l}
0.655 \\
0.158 \\
0.187
\end{array}\right]=\left[\begin{array}{l}
2.006 \\
0.476 \\
0.563
\end{array}\right], \\
& \lambda_{\max }^{\prime}=3.028
\end{aligned}
$$$$
\text { C.I. }=0.014 \text {, R.I. }=0.5149 \text {, C.R. }=\text { C.I. } / \text { R.I. }=0.02718<0.1 \text {, }
$$
then the consistency of matrix $\mathrm{A}^{\prime}$ is verified. verifies the consistency of matrix A. So the weight of learning support environment, personal and content in L2 regarding the whole teaching course is:

$$
\begin{aligned}
& \omega_{z}\left(x_{1}\right)=0.643 \times 0.364=0.257, \\
& \omega_{z}\left(x_{2}\right)=0.167 \times 0.367=0.059, \\
& \omega_{z}\left(x_{3}\right)=0.189 \times 0.367=0.08 .
\end{aligned}
$$

Therefore, a given teaching course in distant education can be graded and evaluated according to its L1 and L2 index. By the comprehensive evaluation model $y_{i}=f\left(\omega, x_{i}\right)$, we can get the comprehensive evaluation value. Judge whether this teaching course of distant education is qualified or good by comparing and sorting with $y_{i}$ from the final calculation with the weight. Improvements can be made if necessary. Their weight can further be calculated as Figure 6 .

\begin{tabular}{|c|c|c|c|}
\hline L1 Index/Weight & L2 Index/Weight & 2010(Spring) & 2010(Autumn ) \\
\hline \multirow{3}{*}{ Import course/0.315 } & Teachers /0.15 & 8 & 8 \\
\cline { 2 - 4 } & Students /0.12 & 8 & 7 \\
\cline { 2 - 4 } & Resources /0.045 & 8 & 7 \\
\hline \multirow{4}{*}{$\begin{array}{c}\text { Learning } \\
\text { support/0.375 }\end{array}$} & $\begin{array}{c}\text { Supporting learning } \\
\text { environment /0.234 }\end{array}$ & 6 & 3 \\
\cline { 2 - 4 } & $\begin{array}{c}\text { Supporting } \\
\text { personnel /0.057 }\end{array}$ & 7 & 7 \\
\cline { 2 - 4 } & $\begin{array}{c}\text { Supporting content } \\
/ 0.084\end{array}$ & 7 & 7 \\
\hline $\begin{array}{c}\text { Teaching } \\
\text { Evaluation/0.31 }\end{array}$ & $\begin{array}{c}\text { Student assessment } \\
\text { /0.15 }\end{array}$ & 6 & 5 \\
\cline { 2 - 4 } & $\begin{array}{c}\text { Course evaluation } \\
/ 0.16\end{array}$ & 5 & 5 \\
\hline
\end{tabular}

Figure 6. Weight of Comprehensive Evaluation

By comprehensive linear weighted method, apply the linear model $y=\sum_{j=1}^{m} \omega_{j} x_{j}$ to evaluate, with the comprehensive evaluation value of the learning course of 
the distant education of 2010 (Spring) as

$y_{1}=\sum_{j=1}^{8} \omega_{j} x_{j} \quad=6.7 \quad$ and $2010 \quad$ (Autumn)

as $y_{2}=\sum_{j=1}^{8} \omega_{j} x_{j}=6.8$, we can see that of 2010 (Autumn)

is better.

\section{CONCLUSION}

Quality evaluation plays a very important role in distant education. Research on the evaluation and analysis of quality and the related technology helps provide a clear picture about the development and future of the present distant education. The evaluation and analysis of quality and the application of technology link all the aspects in technology, contents, and the organizational management together into a whole, and ensure a stable and orderly operation throughout the distant education process. At the same time, they give the evidence for assessing the quality and the guarantee for high quality distant education and high efficiency. To apply this method of evaluation in Internet education institutes, it helps identify the strengths and weakness so that improvements can be made in time for higher efficiency and further development. Thus the quality of designing and constructing the resources for distant education can be improved to get the management to be more scientific, coordinate, and unified.

\section{REFERENCES}

[1] Peter G.,Michael S.,Christine S.,Sue T.Competence for online teaching:A special report. Educational Technology Research and Development,2007,Vol(1), pp:65-72.

[2] Gold.A Constructivist Approach to Online Training for Online Teacers,Http://www.sloanc.org/publications/pdf $/ \mathrm{v}$ 5n1_gold.pdf.

[3] Giding Phil.Online teacher communities and continuing professional development.Teacher Decelopment,2005,Vo$1.5, \mathrm{pp}: 34-46$
[4] Hoore Julie,Barab Sasha.The Inquiry Learning Forum:A Community of Practice Approach to Online Professional Development.TechTre-nds,2006, Vol.4(3), pp:44-49.

[5] Martin.Evaluating Online Teaching and Learning.Information Services\&Use, 2008, Vol.8(3), pp:145-151.

[6] Rovai, A. P. In search of higher persistence rates in distance education.The Internet and Higher Education, 2007,vol.6,pp:7-16.

[7] Innovations in distance education: An emerging set of guiding principles and practices for the design and development of distance education.www.worldcampus.psu.edu/ide/docs/guiding_principles.pdf.

[8] Shea, P., Sau Li, C., A study of teaching presence and student sense of learning community in fully online and web-enhanced college courses, The Internet and Higher Education, 2008, vol.9, pp:175-190.

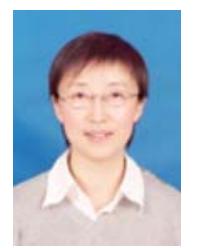

Dan $\mathrm{Mu}$, graduated from Xi'an International Studies University in 1986, and got her Master of English Language and Literature from the same university in 2002; attended IELTS course design at Leeds University, UK, in 2003; a visiting professor to Westminster University and Stephen College ,USA, teaching Chinese

culture in 1998.

She had been an associate professor of English in the areas of Interpreting and Cross-Culture Communication, Xi'an International Studies University till 2006. She worked as the communication manager and business analyst for EC Wise, an American Database company, for three years. Now she is back to teaching in Xi' an International Studies University.

To apply the knowledge and experience gained in IT industry to education, she has published 8 journal papers and one book in the areas of Interpreting, Cross-Culture Communication, and E-learning.

Mingli, Liu, graduated from Xi'an International Studies University in 1985 and finished his MBA course in Southwest University in 2002.

He has been an associate professor of business management in the areas of vocational education and E-learning in Chengdu Neusoft Institute of Information since 2003.

He has published 12 journal papers in the field of vocational education and E-learning 